\title{
Writer's Cramp and Tremor Due to Brain Tumor
}

\author{
I. Milanov and D. Georgiev
}

\begin{abstract}
Writer's cramp is frequently associated with hand tremor and with other focal dystonias. Sometimes brain infarction, haemorrhage, arterio-venous malformations or tumors are found to cause symptomatic focal dystonias. A 44-year-old man came to our attention due to writer's cramp of his right hand and postural $6-8 \mathrm{~Hz}$ tremor. About three months after the onset of the disease the tremor and dystonia disappeared, while a right hemiparesis gradually appeared. Cranial computed tomography showed a hypodense nonhomogeneous lesion in the left cerebral hemisphere parietally, that was assumed to represent a cystic tumor. The patient underwent craniotomy and the histological diagnosis revealed an astrocytoma (Grade II-III). In conclusion our findings confirm the common anatomical basis of symptomatic focal dystonia and tremor. Both can appear after disruption of the pathways within and adjacent to the basal ganglia.
\end{abstract}

\begin{abstract}
RÉSUMÉ: Crampe de l'écrivain et tremblement dus a une tumeur cérébrale. La crampe de l'écrivain est souvent associée au tremblement de la main et à d'autres dystonies focales. L'infarctus cérébral, l'homorragie, une malformation artério-veineuse ou une tumeur ont parfois été identifiés comme la cause d'une dystonie focale symptomatique. Un homme de 44 ans a consulté pour une crampe de l'écrivain à la main droite et un tremblement postural de 6-8 $\mathrm{Hz}$. Trois mois après le début de la maladie, le tremblement et la dystonie sont disparus et une hémiparésie droite s'est installée graduellement. Une tomographie crânienne a montré une lésion non homogène hypodense dans l'hémisphère pariétal gauche qui a été interprétée comme étant une tumeur kystique. Le patient a subi une crâniotomie et l'histologie a montré qu'il s'agissait d'un astrocytome de grade II-IIl. Nos observations confirment le fondement anatomique commun de la dystonie focale et du tremblement. Les deux peuvent survenir suite à une perturbation des voies de transmission dans et autour du noyau lenticulaire, du noyau caudé, de l'avantmur et du noyau amygdalien.
\end{abstract}

Can. J. Neurol. Sci. 1995; 22: 59-61

Evidence from the last decade, points to an organic origin of writer's cramp. ${ }^{1,2}$ This is a focal dystonia, frequently associated with hand tremor and with other focal dystonias. ${ }^{1-3}$

Etiologically, dystonias can be divided into idiopathic and symptomatic. ${ }^{4}$ The idiopathic focal dystonias might be a part of idiopathic generalized dystonia. ${ }^{4}$ The symptomatic focal dystonias might be subdivided into dystonia caused by different inherited degenerative neurological diseases, and to those caused by lesions of the contralateral nucleus caudatus and putamen or the connections between them..$^{4-7}$ Sometimes brain infarction, haemorrhage, arterio-venous malformations or tumors were found to cause focal dystonias. ${ }^{4,8.9}$ Writer's cramp due to a paramedian frontal meningeoma has been reported. ${ }^{10}$ However we are not aware of reports for writer's cramp associated with postural tremor caused by brain tumor.

\section{CASE Report}

A 44-year-old, right-handed man came to our attention due to cramp of his right hand, pain and tremor. He was in good health until March 1993 when he started complaining of cramp in his right hand every time he tried to write. The patient was a policeman and his profession required a lot of writing. During next three weeks the writer's cramp worsened and tightness and pain in the arm muscles appeared. Tremor of his right hand appeared when he attempted to write. Initially his complaints were associated only with writing, but one month after the onset of the disease, the tremor became constant with every action of his right hand. His family history was negative.

Neurological examination revealed no motor weakness or sensory deficit. Tendon reflexes and muscle tone were normal, and no Babinski sign was found. There was a postural tremor in the right upper extremity with a frequency of 7-8 $\mathrm{Hz}$ involving flexion and extension of the fingers and hand. No resting or intentional tremor was found. Cramping of the hand muscles involving all the fingers occurred each time the patient tried to write. No hand cramping occurred when the patient performed different hand tasks.

Laboratory examination was normal for blood and liver function studies, ceruloplasmin, and copper content. Electromyogram recordings of the tremor revealed bursts of alternating electromyographic activity in agonist-antagonists couples, with irregular amplitude and periodicity $(6-8 \mathrm{~Hz})$ (Figure 1). Cranial computed tomography with contrast (CT) was normal. A diagnosis of writer's cramp was made and treatment with baclofen and anticholinergic drugs was tried without any success.

About three months after the onset of the disease the hand tremor disappeared, although the cramps persisted for a further three weeks.

From the Medical University Hospital - IV klm., III Neurological Clinic. Sofia, Bulgaria

RECEIVED MARCH 31. 1994. ACCEPTED IN FINAL FORM JULY 12. 1994.

Reprint requests to: Ivan Milanov, $\mathrm{MD}, \mathrm{PhD}$, Medical University Hospital - IV kilometer, III Neurological Clinic, Blvd. Tzarigradsko shosse - IV kilometer. Sofia 1113. Bulgaria. 
The right arm became weak, followed by the right leg. Several seizures of a few minutes duration, appeared in his right arm, although the patient remained alert and oriented. Subsequently, difficulty in naming was observed and a diffuse headache appeared.

He was admitted to the hospital at the end of July, 1993. Neurological examination revealed a mild right hemiparesis, more severe in the arm than in the leg, with hyperactive tendon reflexes, but without Babinski's sign. Muscle tone was normal. Central lesion of the right facial nerve was found. Neither tremor, nor action dystonia were evident. A single seizure of the right arm with a Jacksonian character was observed. Predominantly motor aphasia was evident.

Cranial computed tomography with contrast now showed a large, well defined, hypodense, nonhomogeneous lesion with marked surrounding edema and displacement, located in the left cerebral hemisphere parietally, that was assumed to represent a cystic tumor (Figure 2). The patient underwent craniotomy, the tumor was partially extirpated, and the histological diagnosis revealed an astrocytoma (Grade II-III). After the operation the right hemiparesis persisted, while no action dystonia or tremor were evident. Radiotherapy was not received by the patient.

\section{Discussion}

Our patient was characterized as having simple, nonlocalized writer's cramp, as he had difficulty performing only one specific task and the cramps involved more than three fingers. ${ }^{2}$ Dystonia was the initial manifestation of the disease, soon followed by tremor. These were observed early in the course of the disease, when the CT was negative, possibly because the lesion was too small.

Symptomatic hemidystonia as a symptom of a cerebral tumor is rare, " but was reported after astrocytoma involving the caudate nucleus, putamen or thalamus. ${ }^{12.13}$ Such lesions are regarded as the anatomical correlate of hemidystonia. ${ }^{12,14}$ Focal dystonias might be caused by lesions of the contralateral nucleus caudatus and putamen or the connections between them. ${ }^{4-7}$ Hand dystonia has been related to lesions of the posterolateral thalamic nuclei and rarely to lesions of the caudate nucleus, putamen and parietal or frontal cortex. ${ }^{10,12,14}$ There is a well-developed somatotopic organization within the basal ganglia. ${ }^{15}$ It is possible that a strategically situated lesion in the basal ganglia could be responsible for a very discrete focal abnormality. With the tumor enlarging, focal dystonia might become hemidystonia. ${ }^{10}$ The location of lesions causing symptomatic focal dystonia suggests that it may be produced by abnormal thalamic-mediated input to premotor and ultimately motor cortex from the basal ganglia. ${ }^{10.12}$ Thus a lesion anywhere in the striatopallidothalamic connections with the premotor cortex will release the premotor cortical activity from thalamic control and cause symptomatic dystonia. ${ }^{10,12}$ All reported striatal and thalamic lesions associated with dystonia also extend into adjacent white matter. ${ }^{16}$ Alteration of the normal functioning of pathways within and adjacent to the basal ganglia and internal capsule may cause dystonia. ${ }^{16}$ There is no evidence that the brain tumor growing in our patient in the parietal region involved the basal ganglia directly. It might have initially involved some pathways adjacent to the basal ganglia, while sparing the pyramidal system and thus causing the focal dystonia and tremor.

There is a controversy about the type of tremor that often accompanies the generalized, segmental or focal, as well as, sporadic or hereditary dystonia. ${ }^{3}$ It is usually clasified as a variant of essential tremor, ${ }^{17}$ but some different clinical and electromyographical features have also been reported. ${ }^{3}$ Some irregularity in tremor amplitude and periodicity and "imperfectly synchronized" bursts in agonist-antagonists couples were supposed to be the main features of so-called "dystonic tremor". 3 Our patient's tremor had some irregularity in tremor amplitude and periodicity, while muscle burst activity was alternating. Sometimes the tremor may be an initial manifestation of dystonia and may be observed without evident dystonic symptoms. ${ }^{3}$ These observations suppose that identical anatomical lesions might be responsible for both tremor and dystonia. The anatomical basis of the tremor associated with dystonia is not clarified.

Similarly situated brain tumors, involving the basal ganglia, or their output to the supplementary motor area might also cause other extrapyramidal symptoms, namely parkinsonism. ${ }^{18-20}$ Although our patient had a tremor with an alternating electromyographic pattern similar to parkinsonian tremor, ${ }^{21}$ it was only postural. Thus, it is unlikely, that some combination of dystonia and parkinsonian tremor was present in our patient.

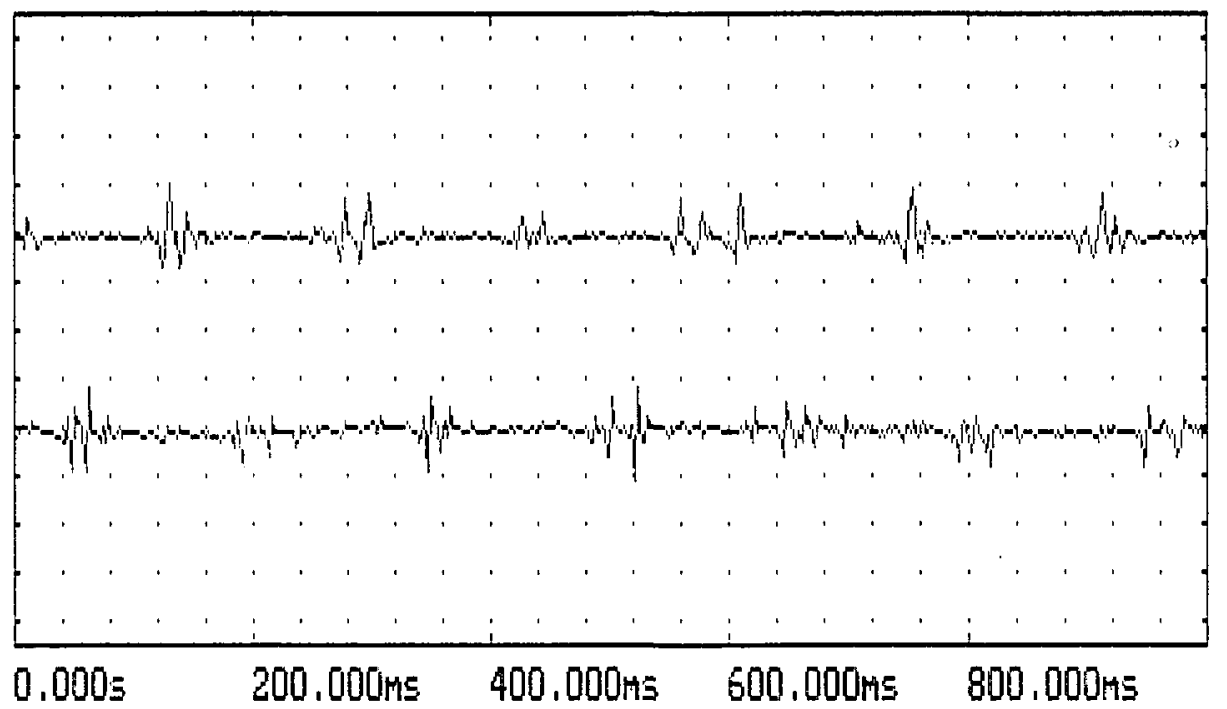

Figure 1: Electromyographic investigation of hand tremor.

An alternating muscle activity recorded from flexor digitorum superficialis and extensor digitorum communis by surface electrodes is evident. 


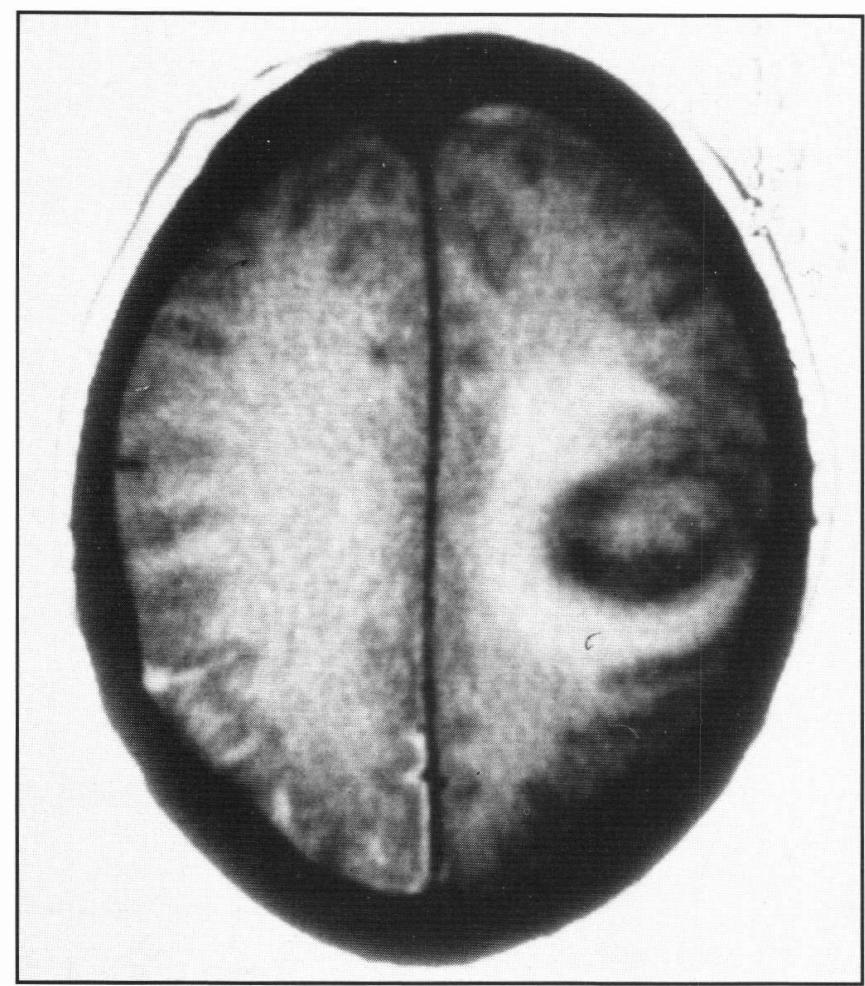

Figure 2: Computed tomography with contrast.

A well defined, hypodense, nonhomogeneous lesion in the left cerebral hemisphere parietally is evident.

The cortico-spinal tract must be relatively spared for dystonia to develop. ${ }^{4.6}$ The involvement of the pyramidal tract is known to interrupt the tremor impulses transmitted from the motor cortex via the internal capsule downward and to cause a disappearance of tremor. ${ }^{22}$ Tremor may also be abolished by surgical intervention in the motor cortex ${ }^{23}$ or by pyramidotomy. ${ }^{24}$ Stereotactic thalamotomy cures tremor on the opposite side of the body without any negative neurological symptoms ${ }^{25.26}$ and may also abolish dystonias. ${ }^{27}$ Tremor was the first symptom that disappeared with the progression of our patient's disease, before any pyramidal involvement was evident. We can assume that the tremor was abolished by minor involvement of the pyramidal tract, while a thalamic lesion is much less likely. However soon hemiparesis appeared, which can explain the suppression of the abnormal movements in our patient with involvement of the pyramidal tract.

In conclusion our findings confirm the common anatomical basis of symptomatic focal dystonia and tremor. Both can appear after disruption of the pathways within and adjacent to the basal ganglia. The cortico-spinal tract must be relatively spared for dystonia to develop.

\section{REFERENCES}

1. Cohen LG, Hallett M. Hand cramps: clinical features and electromyographic patterns in a focal dystonia. Neurology 1988; 38 : $1005-1012$.

2. Sheehy MP, Marsden CD. Writer's cramp: a focal dystonia. Brain 1982; 105: 461-480.

3. Jedynak CP, Bonnet AM, Agid Y. Tremor and idiopathic dystonia. Mov Disord 1991; 6: 230-236.

4. Fahn S. Dystonia: where next? In: Quinn NP, Jenner PG, eds. Disorders of Movement: Clinical, Pharmacological and Physiological aspects. London: Academic Press, 1989: 349-357.
5. Teychenne PF. A review of the neurochemical basis and current rationale for treatment in Huntington's chorea, tardive dyskinesia and dystonia. In: Teychenne PF, ed. Neurotransmitters and Neuropeptides. Taipei: Excerptra Medica, Asia Pacific Congress Series No 32, 1983: 4I-53.

6. Berardelli A. The pathophysiology of dystonia. In: Quinn NP, Jenner PG, eds. Disorders of Movement: Clinical, Pharmacological and Physiological aspects. London: Academic Press, 1989: 251-261.

7. Burke D. Pathophysiological aspects of rigidity and dystonia. $m$ : Benecke R, Conrad B, Marsden CD, eds. Motor Disturbances I. London: Academic Press, 1987: 87-100.

8. Krauss JK, Mohadjer M, Nobbe F, Scheremet R. Hemidystonia due to a contralateral parieto-occipital metastasis: disappearance after removal of the mass lesion. Neurology 1991; 41: 15191520.

9. Lorenzana L, Cabezudo JM, Porras LF, et al. Focal dystonia secondary to cavernous angioma of the basal ganglia: case report and review of the literature. Neurosurgery 1992; 31: 1108-1111.

10. Meyrignac C, Keravel Y, Boulu P, Nguyen JP, Degos JD. Crampe des ecrivains et meningiome frontal gauche. Rev Neurol (Paris) 1988; 144,5: 378-380.

11. Roos RAC, Bruyn GW. Symptomatic dystonias. In: Vinken PJ, Bruyn GW, Klawans HL, eds. Handbook of Clinical Neurology vol 5(49). Amsterdam: Elsevier, 1986: 499-5I8.

12. Marsden CD, Obeso JA, Zarranz JJ, Lang AE. The anatomical basis of symptomatic hemidystonia. Brain 1985; 108: 463-483.

13. Narbona J, Obeso JA, Tunon T, Martinez-Lage JM, Marsden CD. Hemi-dystonia secondary to localised basal ganglia tumor. J Neurol Neurosurg Psychiatry 1984; 47: 704-709.

14. Obeso JA, Gimenez-Roldan S. Clinicopathological correlation in symptomatic hemidystonia. In: Fahn S, Marsden CD, Calne DB, eds. Dystonia 2. Advances in Neurology vol 50. New York: Raven Press, 1988: 113-122.

15. Lee RG. Physiology of the basal ganglia: an overview. Can J Neurol Sci 1984; 11: 124-128.

16. LeDoux MS, Lorden JF. Focal dystonia secondary to cavernous angioma of the basal ganglia: case report and review of the literature. Neurosurgery 1993; 32: 6: 1056.

17. Marsden CD, Obeso J, Rothwell JC. Benign essential tremor is not a single entity. In: Yahr MD, ed. Current Concepts in Parkinson's Disease. Amsterdam:Excerpta Medica, 1983: 31-46.

18. Maillet-Vioud M, Irthum B. Syndrome parkinsonien unilateral en rapport avec un meningiome sphenoidal. Presse Medicale Paris. 1993; 22: 920.

19. Miyagi Y, Morioka T, Otsuka M, Fukui M. Striatal glucose metabolism and $\left[{ }^{18} \mathrm{~F}\right]$ fluorodopa uptake in a patient with tumorinduced hemiparkinsonism. Neurosurgery 1993; 32: 838-641.

20. Kulali A, Tugtekin M, Utkur Y. Erkurt S. Ipsilateral hemi-parkinsonism secondary to an astrocytoma. J Neurol Neurosurg Psychiatry 1991; 54: 653.

21. Shahani BT, Young RR. Physiological and pharmacological aids in the differential diagnosis of tremor. J Neurol Neurosurg Psychiatry 1976; 39: 772-783.

22. Mossuto-Agatiello L, Puccetti G, Castellano AE. "Rubral" tremor after thalamic haemorrhage. J Neurology 1993; 241: 27-31.

23. Bucy PC, Case TJ. Tremor: physiological mechanism and abolition by surgical means. Arch Neurol Psychiatry 1949; 41: 721-746.

24. Walker AE. Cerebral pedunculotomy for the relief of involuntary movements. Parkinsonian tremor. J Nerv Ment Dis 1952; 116: 766-775.

25. Diederich N, Goetz CG, Stebbins GT, et al. Blinded evaluation confirms long-term asymmetric effects of unilateral thalamotomy or subthalamotomy on tremor in Parkinson's disease. Neurology 1992; 42: 1311-1314.

26. Ohye E, Hirai T, Miyazaki M, Shibazaki T, Nakajima H. Vim thalamotomy for the treatment of various kinds of tremor. Appl Neurophysiol 1981; 45: 275-280.

27. Andrew RL, Fowler CJ, Harrison MJG. Stereotaxic thalamotomy in 55 cases of dystonia. Brain 1983; 106: 981-1000. 